Sharif University of Technology
Scientia Iranica
SCIENTIA
I RAN I CA
http://scientiairanica.sharif.edu

\title{
Numerical modelling of flow field in compound channels with non-prismatic floodplains
}

\author{
B. Rezaei* and H. Amiri \\ Department of Civil Engineering, Bu-Ali Sina University, Hamedan, Iran.
}

Received 23 May 2016; received in revised form 19 August 2016; accepted 6 March 2017

\section{KEYWORDS}

Non-prismatic

compound channel;

Numerical modeling;

$k-\varepsilon$ turbulence

model;

Velocity distribution.

\begin{abstract}
In this paper, an attempt was made to study a flow field in compound channels with non-prismatic floodplains. A three-dimensional Computational Fluid Dynamic (CFD) model was used to calculate the velocity distribution, secondary flow circulation, and boundary shear stress in non-prismatic compound channels with two different convergence angles of $3.81^{\circ}$ and $11.31^{\circ}$. The ANSYS-CFX software and the $k-\varepsilon$ turbulence model were used to solve Reynolds Averaged Navier-Stokes (RANS) equations. The results of the numerical modelling were then compared to the experimental data in non-prismatic compound channels with the same convergence angles. The study shows that, more or less, the $k-\varepsilon$ turbulence model is capable of predicting the velocity and boundary shear stress distributions along the flume fairly well, especially for convergence angle of $3.81^{\circ}$. In addition, by increasing relative depth, discrepancy between numerical and experimental data decreases. The results of modelling show that the $k-\varepsilon$ turbulence model is able to predict secondary flow circulations in the main channel, created by the mass exchange between the floodplains and the main channel.
\end{abstract}

(C) 2018 Sharif University of Technology. All rights reserved.

\section{Introduction}

The prediction of velocity and boundary shear stress distribution in compound channels with prismatic floodplains is a difficult task for hydraulics engineers due to the three-dimensional pattern of the flow. In prismatic compound channels, the difference in velocity between the floodplains and the main channel flows creates strong shear layers at interface of the main channel and floodplains. These shear layers produce large-scale turbulent structures, typically large plan form vortices, and the secondary flow circulations with longitudinal axes (see $[1,2])$.

The complexity of the problem rises when dealing with the non-prismatic compound channels. As seen in

\footnotetext{
*. Corresponding author.

E-mail address: b.rezaei@basu.ac.ir (B. Rezaei)
}

Figure 1, in compound channels with converging floodplains, water leaving the floodplains crosses over water flowing into the main channel, and this mass exchange increases interaction and, consequently, momentum exchange between subsections; see [1,3-7]. This extra momentum exchange should also be taken into consideration in the flow modelling. Having studied force and momentum balance in compound channels with narrowing floodplains, Rezaei and Knight [7] revealed that mass exchange between the floodplains and the main channel accelerates the flow in the main channel. Bousmar and Zech [8] suggested that the effects of the geometrical exchange discharge could be considered as an additional head loss [7].

Pezzinga [9] used a nonlinear $k-\varepsilon$ turbulence model to predict the uniform flow in a prismatic compound channel. He found that the proposed model is able to predict the secondary current, created by the anisotropy of normal turbulent stress. In addition, Kang and Choi [10] investigated the flow field in 


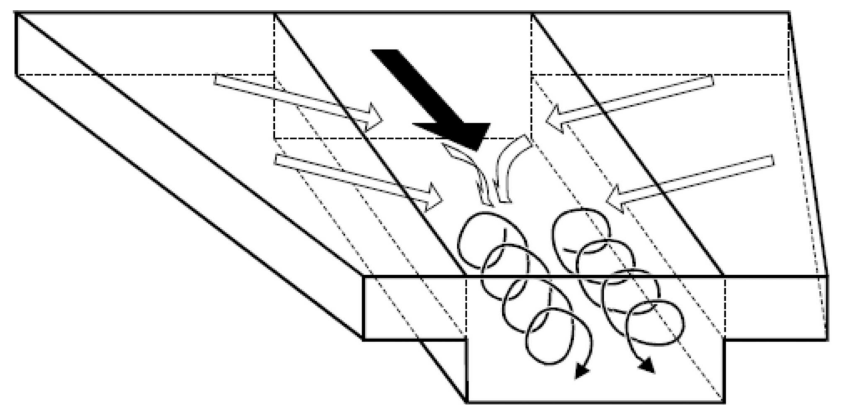

Figure 1. Schematic view of the flow structure in a compound channel with narrowing floodplains [2].

a prismatic compound channel using the Reynolds Stress Model (RSM). They used the experimental data of Tominaga and Nezu [2] to verify the results of numerical modelling.

Cokljat [11] modelled flows in channels using two turbulence models, i.e., Reynolds Stress Transport and $k-\varepsilon$ turbulence models, in combination with a nonlinear stress strain relationship. He found that the Reynolds Stress Transport (RST) model is able to predict the strength and location of secondary flow cells and their role in displacing the maximum velocity to below the free surface; however, in contrast, the nonlinear $k-\varepsilon$ model failed to reproduce this result. Both models predicted the shear stress equally well.

Wright et al. [12] used $k-\varepsilon$ and various Reynolds Stress models to investigate flow characteristics in the open channel with a trapezoidal cross-section. The results showed that while all the models generally gave similar predictions concerning the bulk features of the flow, there is a clear difference in the secondary flow characteristics. The $k-\varepsilon$ model failed to show any recirculation, and the Reynolds Stress models showed some recirculation in varying degrees.

Beaman [13] investigated a flow field in in-bank and over-bank channels using Large Eddy Simulation (LES). He reveals that the LES can accurately predict the flow characteristics, especially the secondary flow circulations in inbank and overbank flows in channels with different depths and width ratios. Bombardelli et al. [14] modelled flow over the steep stepped spillways using two turbulence models including the $k-\varepsilon$ and RNG $k-\varepsilon$ models. They showed that both turbulence models provided very similar results that are in good agreement with experimental data. Bayon et al. [15] used the RNG $k-\varepsilon$ turbulence model to study a steady hydraulic jump at low Reynolds number. They also used a two-phase Volume Of Fluid (VOF) approach to tracking the air-water interface. Gholami et al. [16] experimentally and numerically studied the flow field in a strongly curved $90^{\circ}$ open channel bend. They used the RNG $k-\varepsilon$ turbulence model and the Volume Of Fluid (VOF) method to simulate velocity and water surface profile. They found that the RNG $k-\varepsilon$ model and VOF method are capable of modelling the flow pattern in open channels with a strongly curved bend.

The main aim of the present work is to investigate whether or not the $k-\varepsilon$ turbulence model is able to predict the effects of flow depth and floodplain convergence angles on the flow field (including the velocity and boundary shear stress distributions, secondary flow circulation, and water surface profile) in non-prismatic compound channels.

\section{Experimental apparatus and procedure}

Experiments were conducted by Rezaei [1] using an $18 \mathrm{~m}$ flume of the Birmingham University, Department of Civil Engineering. All experiments were performed in a rectangular compound channel, $18 \mathrm{~m}$ long, $1.198 \mathrm{~m}$ wide, $0.4 \mathrm{~m}$ deep, and average bed slope of $S_{o}=$ $2.003 \times 10^{-3}$. The PVC material was used to construct the rigid and smooth compound channel boundaries, both for the main channel of $0.398 \mathrm{~m}$ width and $0.05 \mathrm{~m}$ depth, and also for the floodplains $0.4 \mathrm{~m}$ wide. Two sets of experiments were carried out in non-prismatic compound channels, converging from $0.4 \mathrm{~m}$ to $0 \mathrm{~m}$ along $6 \mathrm{~m}$ and $2 \mathrm{~m}$ length (convergence angles of $\theta=3.81^{\circ}$ and $\theta=11.31^{\circ}$ ). For experiments in compound channels with non-prismatic floodplains, the main channel and floodplains were isolated using Lshaped aluminium sections to make different convergence angles of $\theta$ (Figure 2).

An overbank flow in a non-prismatic compound channel tests is represented by NPC. In non-prismatic compound channel tests, the letter code is followed by two code numbers: The first refers to the convergence length; the second code number stands for the relative depth in the center of converging flume portion [7].

At the downstream flume end, a series of three

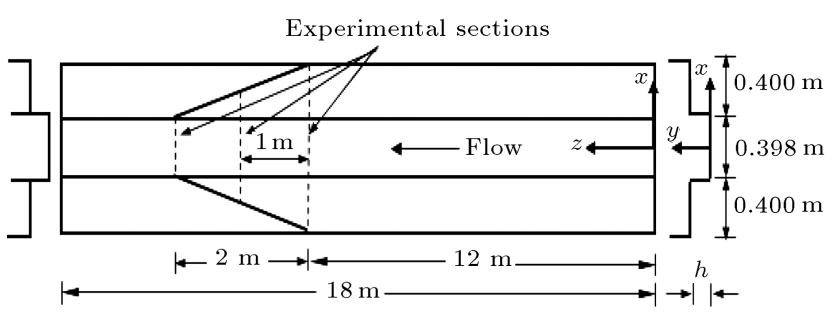

(a)

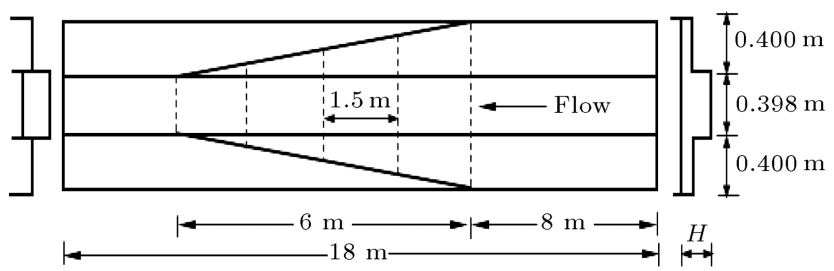

(b)

Figure 2. Plan view of compound channels with non-prismatic floodplains; convergence angles of (a) $11.31^{\circ}$ (NPC2), and (b) $3.81^{\circ}$ (NPC6) [7]. 
adjustable tailgates controlled a specific flow depth in the middle of the converging flume part. Due to a change in floodplain geometry, the flow condition in non-prismatic compound channels is not uniform and, based on the downstream flow depth imposed by tailgates, different water surface profiles in the upstream prismatic and the converging part of flume have been performed [7]. For each discharge, the downstream water surface elevation was adjusted using the tailgates such that the backwater profile reached a given specific relative depth, $D_{r}=(H-h) / H$ (in which $H$ is the flow depth in main channel, and $h$ is the bankfull height), in the middle of the converging part of the fume at $x=13 \mathrm{~m}$ and $x=11 \mathrm{~m}$ for NPC2 and NPC6, respectively [7].

\subsection{Depth-averaged velocity measurement}

A Novar Nixon miniature propeller current meter with accuracy of $\pm 0.048 \mathrm{~m} / \mathrm{s}$ was used to measure the depthaveraged velocity distribution at different positions along the converging part of the flume (Figure 2). The point depth-averaged velocity was measured laterally every $25 \mathrm{~mm}$ at a depth of $0.6(H-h)$ from the water surface on the floodplains and $0.6 H$ in the main channel.

Measuring the local velocities was done in three selected sections (at the beginning, the end, and in one section in the middle of the convergence) across the whole cross-section, laterally every $25 \mathrm{~mm}$ and vertically every $10 \mathrm{~mm}$.

\subsection{Boundary shear stress measurement}

Boundary shear stress distributions were also measured using a Preston tube with $4.77 \mathrm{~mm}$ outer diameter (see [17]). These experiments were carried out in the same sections, where depth-averaged velocity measurements were done. Boundary shear stress distribution was measured around the wetted channel perimeter at $10 \mathrm{~mm}$ vertical intervals on the walls and $25 \mathrm{~mm}$ transverse intervals on the bed with accuracy of $\pm 0.076 \mathrm{~N} / \mathrm{m}^{2}[7]$.

\section{Mathematical model}

\subsection{The Navier-Stokes equations}

The Navier-Stokes equations describe the general motion of turbulent flow, and their derivation can be found in a CFD textbook such as Davidson [18]. The NavierStokes equations are considered an expression of the conservation of mass and momentum. The equation for the mass conservation is called the continuity equation and is expressed for an incompressible fluid flow as in the following:

$$
\frac{\partial U_{j}}{\partial x_{j}}=0
$$

where $U_{j}$ is time-averaged components of velocity:

$$
U_{j}=\frac{1}{\Delta t} \int_{t_{1}}^{t_{2}} u_{j} d t
$$

where $u_{j}$ is velocity components and $t$ is time. In addition, conservation of momentum is an expression of the second low of Newton and can be explained as follows:

$$
-\frac{\partial P}{\partial x_{i}}+\frac{\partial}{\partial x_{j}}\left(\tau_{i j}-\rho \overline{u_{i}^{\prime} u_{j}^{\prime}}\right)=\rho\left(\frac{\partial U_{i}}{\partial t}+\frac{\partial U_{i} U_{j}}{\partial x_{j}}\right),
$$

where $P$ is pressure, $\tau_{i j}$ is the molecular stress tensor (including both components of the stress), $\rho$ is the flow density, $\rho \overline{u_{i}^{\prime} u_{j}^{\prime}}$ is called 'turbulent' or 'Reynolds' stresses and can be calculated using the Bossiness Eddy Viscosity turbulence model:

$$
-\rho \overline{u_{i}^{\prime} u_{j}^{\prime}}=\mu_{t}\left(\frac{\partial U_{i}}{\partial x_{j}}+\frac{\partial U_{j}}{\partial x_{i}}\right)-\frac{2}{3} \rho k \delta_{i j},
$$

where $\mu_{t}$ is the turbulence viscosity, $k$ is the turbulence kinetic energy, and $\delta_{i j}$ is the Kronecker delta.

\subsection{The $k-\varepsilon$ model}

The standard $k-\varepsilon$ turbulence model is classified as a two-equation model since it uses two transport equations to describe turbulence [19]. These two transport equations are as follows:

The turbulent kinetic energy equation:

$$
\begin{aligned}
\frac{\partial(\rho k)}{\partial t} & +\frac{\partial}{\partial x_{j}}\left(\rho U_{j} k\right)=\frac{\partial}{\partial x_{j}}\left(\left(\mu+\frac{\mu_{t}}{\sigma_{k}}\right) \frac{\partial k}{\partial x_{j}}\right) \\
& +P_{k}-\rho \varepsilon .
\end{aligned}
$$

The turbulent kinetic energy dissipation rate equation:

$$
\begin{aligned}
\frac{\partial(\rho \varepsilon)}{\partial t} & +\frac{\partial}{\partial x_{j}}\left(\rho U_{j} \varepsilon\right)=\frac{\partial}{\partial x_{j}}\left(\left(\mu+\frac{\mu_{t}}{\sigma_{\varepsilon}}\right) \frac{\partial \varepsilon}{\partial x_{j}}\right) \\
& +\frac{\varepsilon}{k}\left(C_{s 1} P_{k}-C_{s 2} \rho \varepsilon\right),
\end{aligned}
$$

where $k$ is the turbulence kinetic energy and is defined as the variance of the fluctuations in velocity, $\varepsilon$ is the turbulence eddy dissipation (the dissipation rate of the velocity fluctuation). Besides, $C_{s 1}=1.44, C_{s 2}=1.92$, $\sigma_{k}=1.00$, and $\sigma_{e}=1.30$ are turbulence constants. $P_{k}$ is the turbulence production due to viscous forces modelled using:

$$
P_{k}=\mu_{t}\left(\frac{\partial U_{i}}{\partial x_{j}}+\frac{\partial U_{j}}{\partial x_{i}}\right) \frac{\partial U_{i}}{\partial x_{j}}-\frac{2}{3} \frac{\partial U_{k}}{\partial x_{k}}\left(\rho k+3 \mu_{t} \frac{\partial U_{k}}{\partial x_{k}}\right)
$$




\subsection{Numerical simulation}

The Computational Fluid Dynamic (CFD) is a capable computer-based tool for simulating the flow field, heat transfer, and other physical processes of systems. It works by numerically solving the Reynolds-Averaged Navier-Stokes (RANS) equations over an interested region, with specified boundary conditions. The equations will be solved through space and time to gain a numerical explanation of the flow field. The ANSYSCFX software is a commercial CFD code; it solves the RANS equations using the finite volume method [20]. In ANSYS-CFX, the Reynolds-Averaged Navier-Stokes equations are discretized into a system of linear equations. The CFX solver then solves those systems of linearized equations using an algebraic Multi-Grid (MG) method during an iterative procedure.

One advantage of using ANSYS-CFX over other software products is that it offers various validated solutions as well as powerful algorithms and discrete techniques, and is also flexible in implantation of boundary condition via user-defined FORTRAN subroutines [21,22].

\subsection{Simulation of flow field}

The height and width of the domain in the numerical model were adopted exactly the same as those of the experimental flume used by Rezaei [1]. In addition, an important task was to decide which solver should be used. Because flow condition in the flume is not uniform, the Volume Of Fluid (VOF) approach was chosen. Hirt and Nichols [23] revealed that, compared to other methods, the VOF method is more efficient and flexible for treating complicated free boundary configurations.

\subsection{Mesh gridding}

In numerical modelling, an optimal mesh size modification was pursued with the intention of optimal running time computation and accuracy maintenance. It is essential that the numerical models have an appropriately fine mesh to resolve the flow field near the water surface, interface of the main channel and floodplains, and near no-slip boundaries (the regions with high velocity gradients) (see Figure 3 ).

To study the effects of mesh size on flow modelling, three sets of mesh sizes for a compound channel with non-prismatic floodplains converging from $0.4 \mathrm{~m}$ to $0 \mathrm{~m}$ along $2 \mathrm{~m}$ (convergence angle of $11.31^{\circ}$ ) were chosen. The mesh cell sizes were selected such that the average refinement ratio was above the recommended

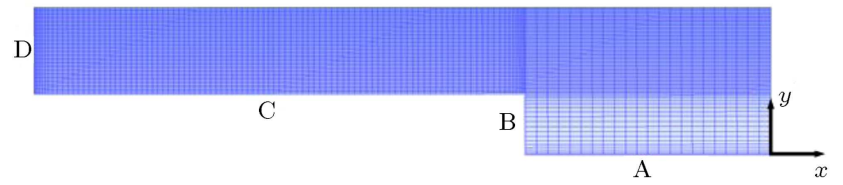

Figure 3. Schematic view of gridding in sections.

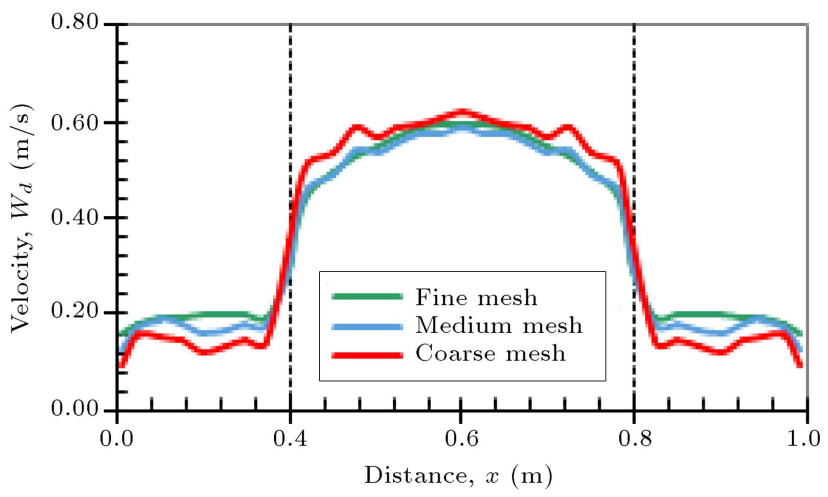

Figure 4. Depth-averaged velocity in the middle of converging flume portion $(z=13)$ for three different mesh sizes and convergence angles of $11.31^{\circ}$.

Table 1. Details of gridding for coarse, medium, and fine meshes.

\begin{tabular}{cccc}
\hline $\begin{array}{c}\text { Element } \\
\text { name }\end{array}$ & $\begin{array}{c}\text { Coarse } \\
(\mathbf{m})\end{array}$ & $\begin{array}{c}\text { Medium } \\
(\mathbf{m})\end{array}$ & $\begin{array}{c}\text { Fine } \\
(\mathbf{m})\end{array}$ \\
\hline A & 0.012 & 0.01 & 0.0055 \\
B & 0.0057 & 0.0037 & 0.0026 \\
C & 0.0059 & 0.0042 & 0.0028 \\
D & 0.0034 & 0.0014 & 0.001 \\
\hline
\end{tabular}

minimum value of 1.3 (see [24]). Using the $k-\varepsilon$ turbulence model and discharge of $15 \mathrm{l} / \mathrm{s}$, the depthaveraged velocity in the middle of the converging flume portion $(z=13 \mathrm{~m})$ was numerically modelled and shown in Figure 4. The numerical uncertainty of the model was evaluated according to Celik et al. [24] with an average value of $3.10 \%$.

For all mesh gridding sizes, the dispersion diagrams of the experimental and numerical data together with an ideal line function $(y=x)$ are presented in Figure 5. As seen in the figure, by increasing the number of nodes and, consequently, decreasing mesh sizes, the dispersion of data around the ideal line decreases. Details of gridding are shown in Table 1.

It should be noted that the mesh spacing was chosen such that the dimensionless distance to the wall, $y^{+}\left(=y u^{*} / v\right)$, could be mostly in the range of $15<y^{+}<400$.

\subsection{Boundary conditions}

The solution of the flow field was obtained and carried out using ANSYS-CFX software with the $k-\varepsilon$ turbulence model and an iteration procedure with accuracy of $1 \times 10^{-4}$. At the flume inlet, the Dirichlet boundary conditions were used for velocity and turbulence. The boundary conditions are as follows:

(a) Uniform velocity distribution at the flume inlet for water;

(b) Hydrostatics pressure condition at the outlet; 
(c) Smooth solid wall with no-slip condition in the main channel and on the floodplains walls and beds, because the flume cross-section has been made using PVC material with almost no roughness.

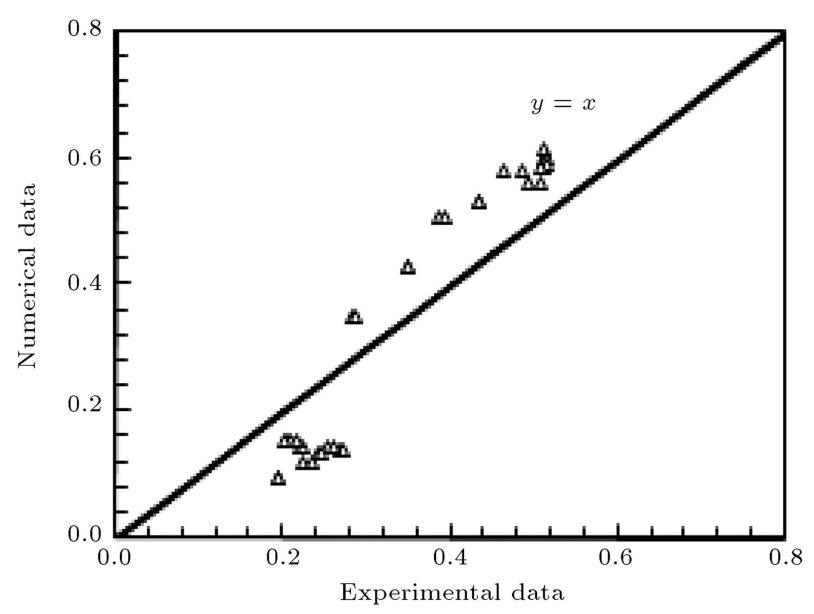

(a)

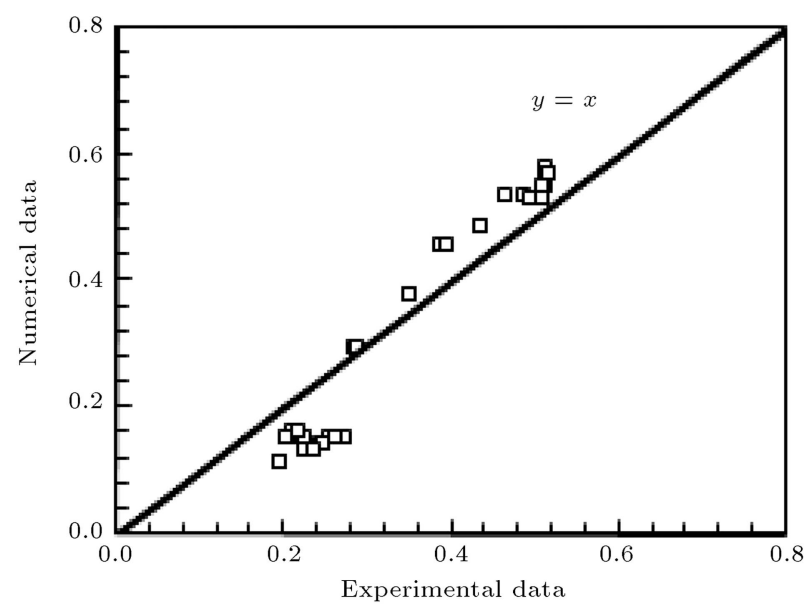

(b)

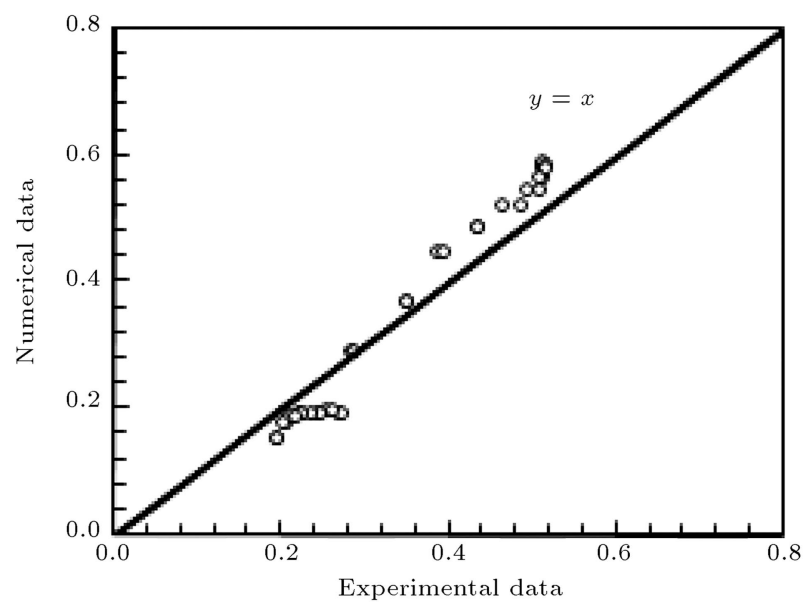

(c)

Figure 5. Dispersion diagram of velocity for mesh size validation analysis: (a) Coarse mesh, (b) medium mesh, and (c) fine mesh.

\section{Results and discussion}

\subsection{Velocity distributions}

To study the effects of the flume convergence angles on the flow field, the stream-wise depth-averaged velocity in the non-prismatic compound channel with two convergence angles of $3.81^{\circ}$ (NPC6) and $11.31^{\circ}$ (NPC2) and three relative depths of $D_{r}=0.3,0.4$, and 0.5 was modelled using the $k-\varepsilon$ turbulence model. The results of depth-averaged velocity modelled by ANSYS-CFX for two relative depths of 0.3 and 0.5 in three selected sections (at the beginning, in the middle, and at the end of narrowing reach) are shown in Figures 6 to 9 .

As seen in Figures 6 and 8 for convergence angle of $3.81^{\circ}$ (NPC6), the $k-\varepsilon$ turbulence model has the ability to predict the depth-averaged velocity distribution quite well; only at the end of convergence reach (where the compound cross-section is changed to a single

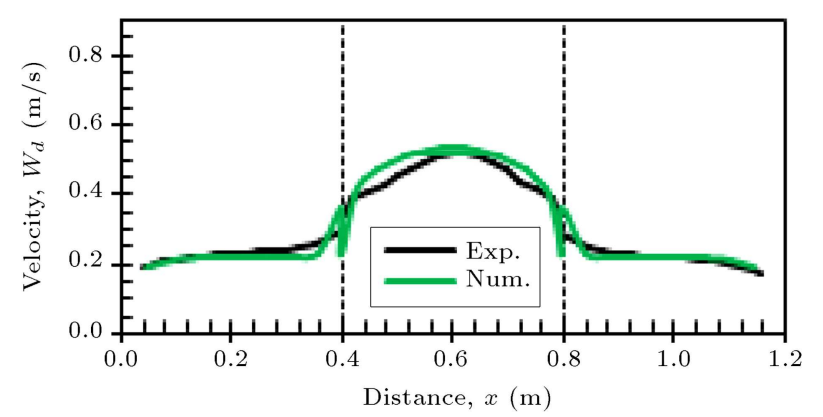

(a)

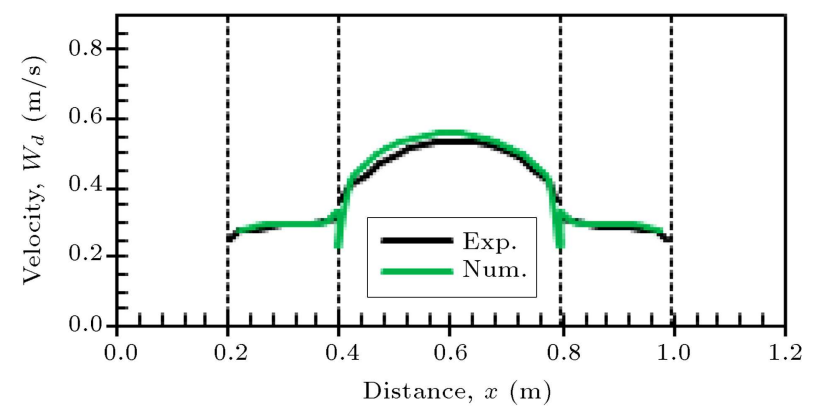

(b)

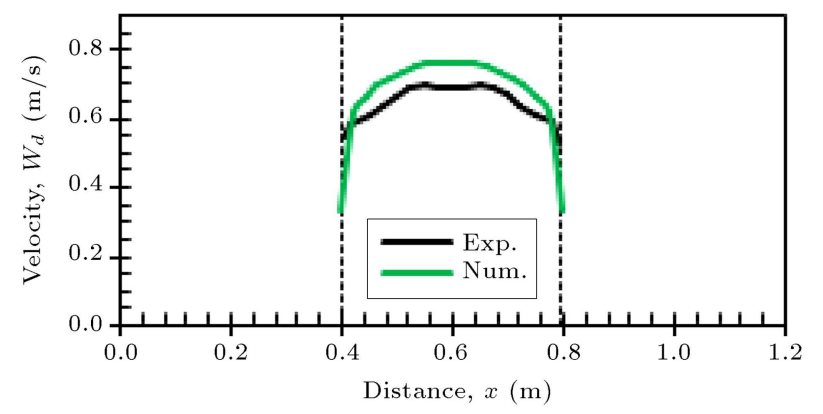

(c)

Figure 6. Depth-averaged velocity distribution modelled using the $k-\varepsilon$ turbulence model along convergence portion for an experimental series of NPC6-0.3: (a) $z=8$ $\mathrm{m}$, (b) $z=11 \mathrm{~m}$, and (c) $z=14 \mathrm{~m}$. 


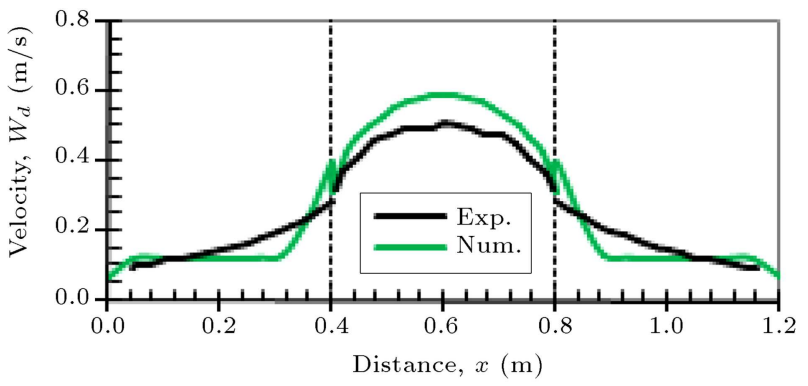

(a)

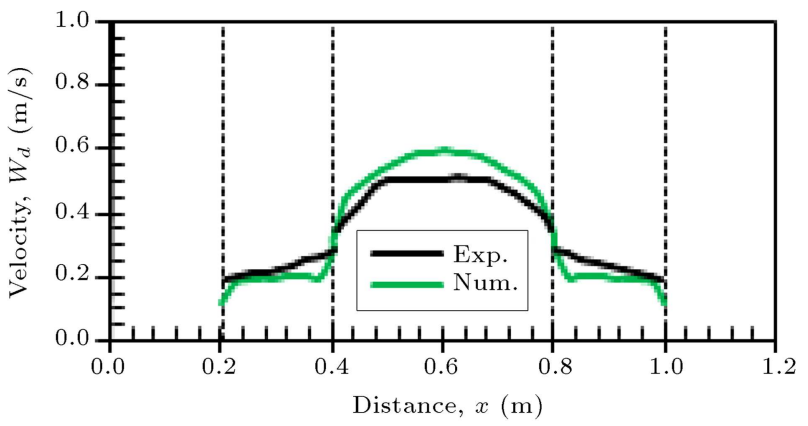

(b)

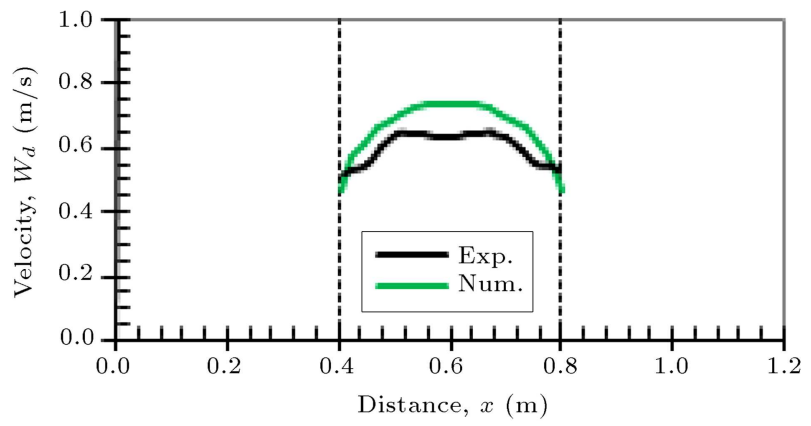

(c)

Figure 7. Depth-averaged velocity distribution modelled using $k-\varepsilon$ turbulence model along convergence portion for an experimental series of NPC2-0.3: (a) $z=12 \mathrm{~m}$, (b) $z=13 \mathrm{~m}$, and $z=14 \mathrm{~m}$.

rectangular section), the numerical modelling slightly overestimates depth-averaged velocity distribution.

For a compound channel with the convergence angle of $11.31^{\circ}$ and relative depth of $D_{r}=0.3$ (NPC2-0.3), the numerical modelling overestimates depth-averaged velocity in the main channel while underestimates it on the floodplains (see Figure 7(b), and (c)). Those differences might be due to inaccuracy of bed roughness in low water depth or disability of the $k-\varepsilon$ turbulence model to predict the secondary flow created by anisotropy of turbulence structure. However, as seen in Figures 8 and 9, by increasing relative depth, discrepancies between experimental and numerical data decrease.

The average velocity in the main channel and on the floodplains for two experimental cases of NPC6 and NPC2 and different relative depths are also calculated using Eq. (8), as shown in Tables 2 and 3:

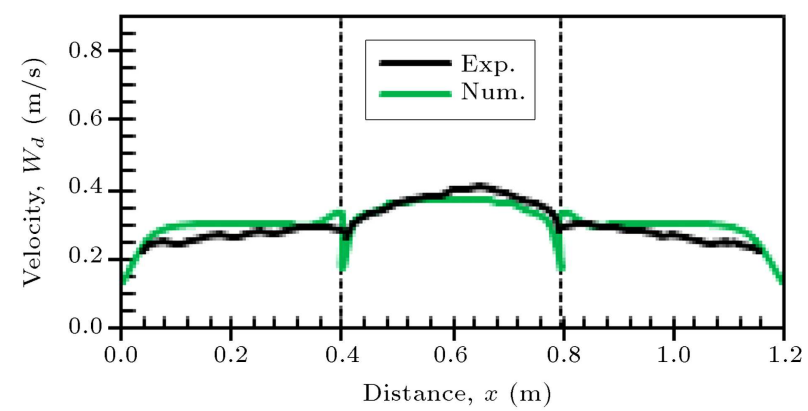

(a)

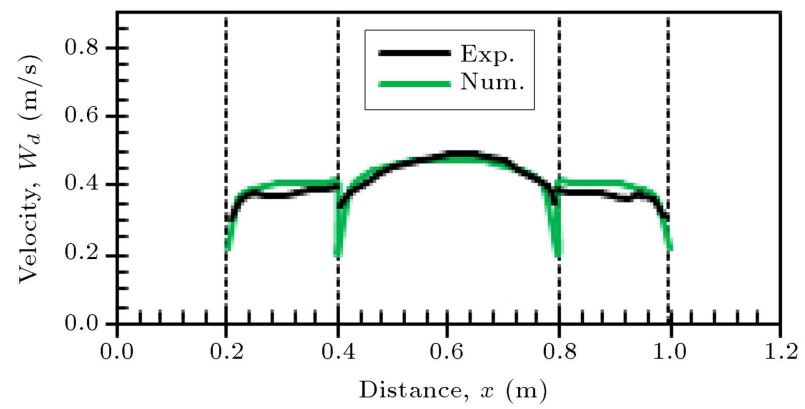

(b)

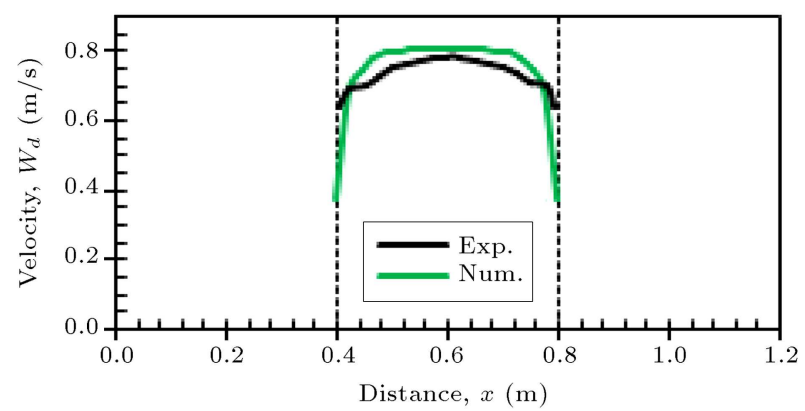

(c)

Figure 8. Depth-averaged velocity distribution modelled using $k-\varepsilon$ turbulence model along convergence portion for an experimental series of NPC6-0.5: (a) $z=8 \mathrm{~m}$, (b) $z=11 \mathrm{~m}$, and (c) $z=14 \mathrm{~m}$.

$$
W=\frac{\sum W_{d i} \Delta A_{i}}{A},
$$

where $W_{d i}$ is the local depth-averaged velocity, $\Delta A_{i}$ is the surrounding sub-areas, and $A$ is the cross-section area.

The differences between the experimental and numerical data of the average velocity for both converging cases were less than $5.5 \%$ in the main channel and $7 \%$ on the floodplains.

The stream-wise velocity distributions in different sections along converging flume portion for experimental cases of NPC2-0.5 and NPC6-0.5 are also modelled and shown in Figure 10.

According to Figure 10(a) and (b), velocity increases along the converging part of the flume. Moreover, as seen, up to the middle section of the convergence, the maximum velocity takes place near 


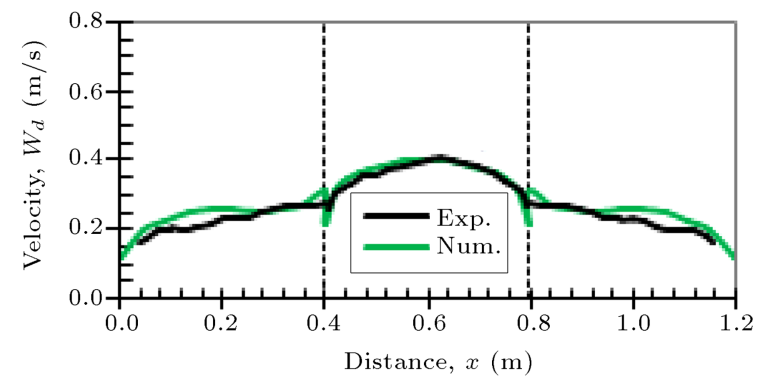

(a)

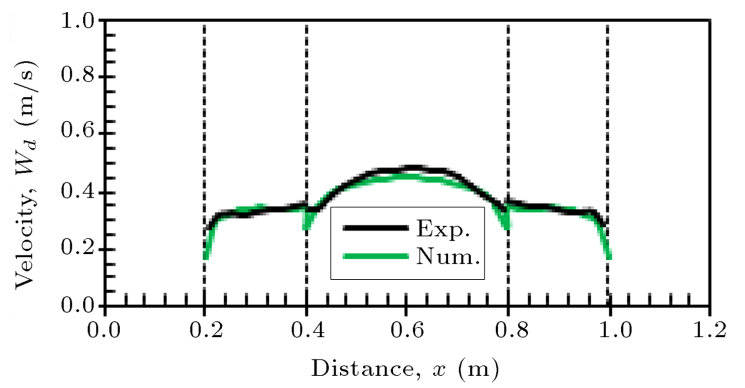

(b)

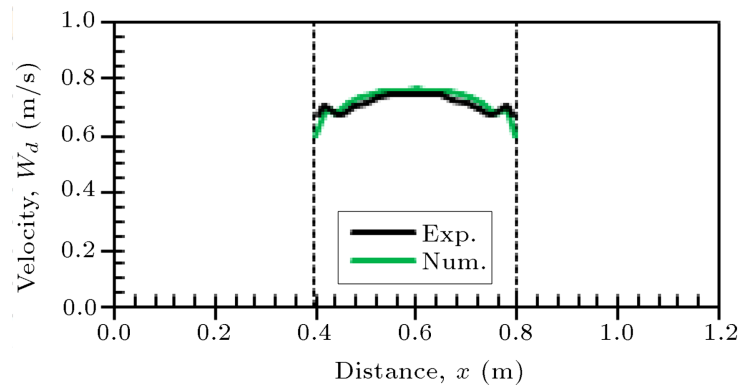

(c)

Figure 9. Depth-averaged velocity distribution modelled using $k-\varepsilon$ turbulence model along convergence portion for an experimental series of NPC2-0.5: (a) $z=12 \mathrm{~m}$, (b) $z=13 \mathrm{~m}$, and (c) $z=14 \mathrm{~m}$.

Table 2. Comparison of average velocities calculated using experimental and numerical data in the main channel ( $\left.W_{m c}\right)$ and on the floodplains $\left(W_{f p}\right)$ for an experimental series of NPC6.

\begin{tabular}{|c|c|c|c|c|c|}
\hline \multirow{2}{*}{ Exp. } & \multirow{2}{*}{$\frac{\text { Exp. section }}{Z(\mathrm{~m})}$} & \multicolumn{2}{|c|}{ Exp. velocity } & \multicolumn{2}{|c|}{ Num. velocity } \\
\hline & & $W_{f p}(\mathrm{~m} / \mathrm{s})$ & $W_{m c}(\mathrm{~m} / \mathrm{s})$ & $W_{f p}(\mathrm{~m} / \mathrm{s})$ & $W_{m c}(\mathrm{~m} / \mathrm{s})$ \\
\hline \multirow{3}{*}{ NPC6-0.3 } & 8 & 0.210 & 0.444 & 0.223 & 0.437 \\
\hline & 11 & 0.281 & 0.477 & 0.281 & 0.478 \\
\hline & 14 & - & 0.636 & - & 0.682 \\
\hline \multirow{3}{*}{ NPC6-0.4 } & 8 & 0.239 & 0.415 & 0.255 & 0.349 \\
\hline & 11 & 0.321 & 0.456 & 0.344 & 0.430 \\
\hline & 14 & - & 0.683 & - & 0.738 \\
\hline \multirow{3}{*}{ NPC6-0.5 } & 8 & 0.264 & 0.370 & 0.285 & 0.337 \\
\hline & 11 & 0.364 & 0.440 & 0.381 & 0.425 \\
\hline & 14 & - & 0.732 & - & 0.741 \\
\hline
\end{tabular}

Table 3. Comparison of average velocities calculated using experimental and numerical data in the main channel $\left(W_{m c}\right)$ and on the floodplains $\left(W_{f p}\right)$ for an experimental series of NPC2.

\begin{tabular}{|c|c|c|c|c|c|}
\hline \multirow{2}{*}{ Exp. } & \multirow{2}{*}{$\begin{array}{c}\text { Exp. section } \\
Z(\mathrm{~m}) \\
\end{array}$} & \multicolumn{2}{|c|}{ Exp. velocity } & \multicolumn{2}{|c|}{ Num. velocity } \\
\hline & & $W_{f p}(\mathrm{~m} / \mathrm{s})$ & $W_{m c}(\mathrm{~m} / \mathrm{s})$ & $W_{f p}(\mathrm{~m} / \mathrm{s})$ & $W_{m c}(\mathrm{~m} / \mathrm{s})$ \\
\hline \multirow{3}{*}{ NPC2-0.3 } & 12 & 0.156 & 0.448 & 0.159 & 0.509 \\
\hline & 13 & 0.230 & 0.465 & 0.194 & 0.498 \\
\hline & 14 & - & 0.612 & - & 0.662 \\
\hline \multirow{3}{*}{ NPC2-0.4 } & 12 & 0.180 & 0.405 & 0.197 & 0.433 \\
\hline & 13 & 0.267 & 0.448 & 0.252 & 0.450 \\
\hline & 14 & - & 0.649 & - & 0.683 \\
\hline \multirow{3}{*}{ NPC2-0.5 } & 12 & 0.219 & 0.359 & 0.243 & 0.359 \\
\hline & 13 & 0.320 & 0.416 & 0.316 & 0.400 \\
\hline & 14 & - & 0.688 & - & 0.718 \\
\hline
\end{tabular}




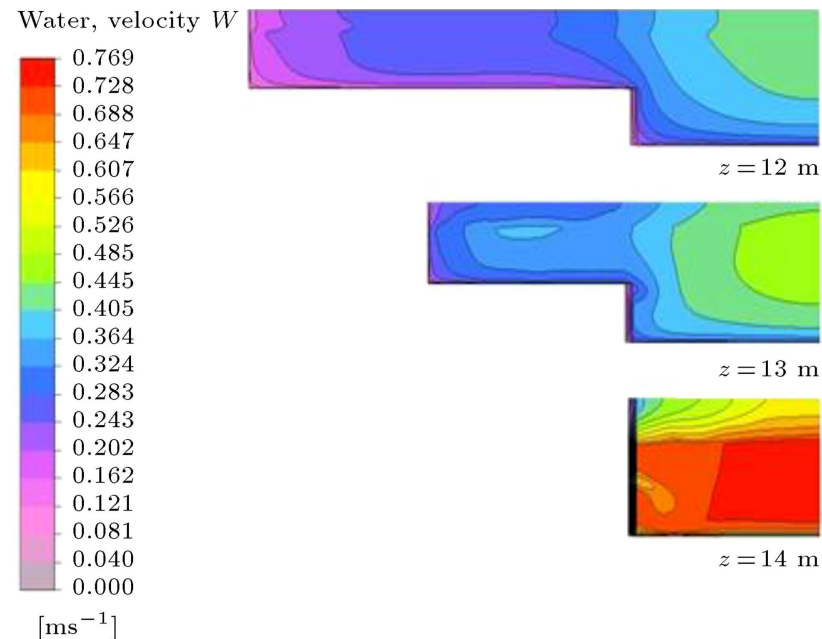

(a)

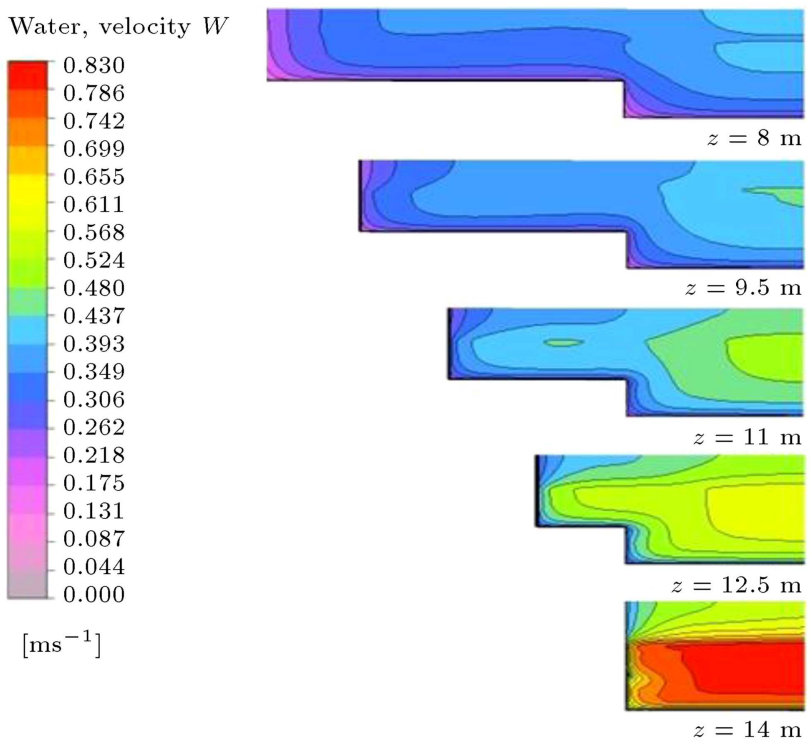

(b)

Figure 10. Velocity distribution along the converging part of the flume for an experimental series of (a) NPC2-0.5 and (b) NPC6-0.5.

the water surface; however, in the second half part of the convergence, due to development of the secondary flow cells, the maximum velocity moves toward the main channel bed (the same observation was made by Rezaei and Knight [7]). In addition, the bulging of the isovels towards the main channel from the floodplain edges in the second half of the convergence reach is characteristic of flows in which the circulation of secondary currents is detected.

\subsection{Boundary shear stress distributions}

Boundary shear stress distribution is another essential parameter in river engineering when studying riverbank protection and sediment transport. In this numerical study, in order to model boundary shear stress, the wetted perimeter was divided into different boundary

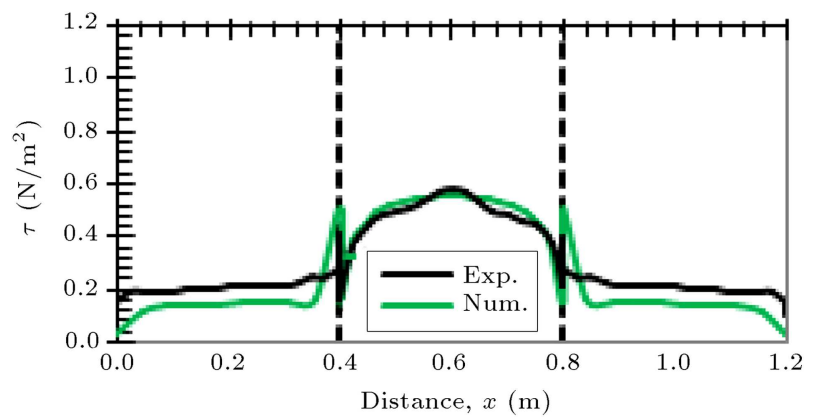

(a)

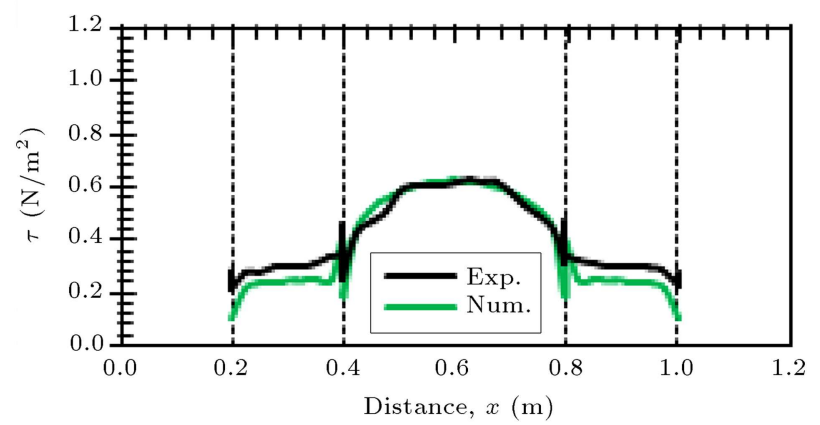

(b)

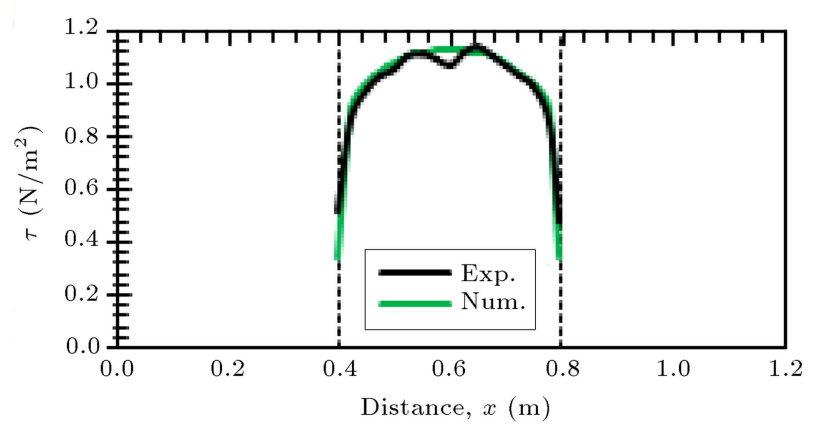

(c)

Figure 11. Boundary shear stress modelled using $k-\varepsilon$ turbulence model along convergence portion for an experimental series of NPC6-0.3: (a) $z=8 \mathrm{~m}$, (b) $z=11$ $\mathrm{m}$, and (c) $z=14 \mathrm{~m}$.

elements. The results of boundary shear stress distributions calculated using the $k-\varepsilon$ turbulence model, for two converging cases and relative depths of 0.3 and 0.5 , were then compared to experimental data (see Figures 11 to 14 ).

Figures 11 and 12 reveal that the $k-\varepsilon$ turbulence model slightly overestimates the boundary shear stress distributions in the main channel, while the mentioned model underestimates it on the floodplains. In addition, as seen in Figures 13 and 14, by increasing water depth (relative depth), the results of the shear stress modelling have been improved. As mentioned before, the $k-\varepsilon$ turbulence model is not able to predict secondary flow cells created by anisotropy of turbulence structure; as a result, by reducing relative depths, the difference between experimental and numerical data of the boundary shear stress distributions increases. 


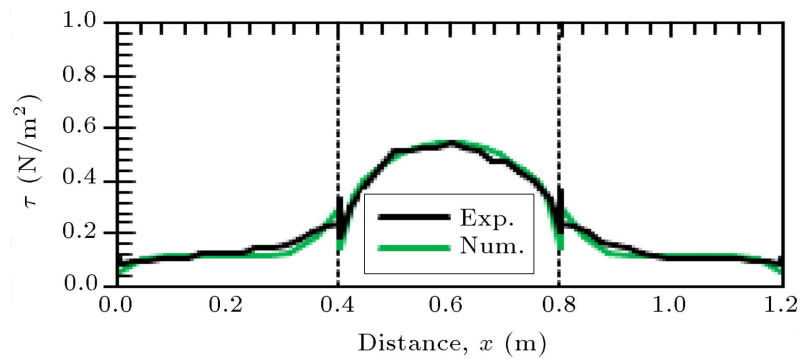

(a)

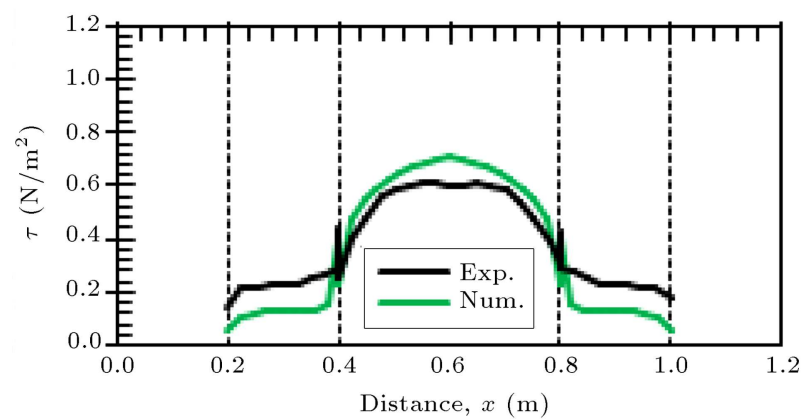

(b)

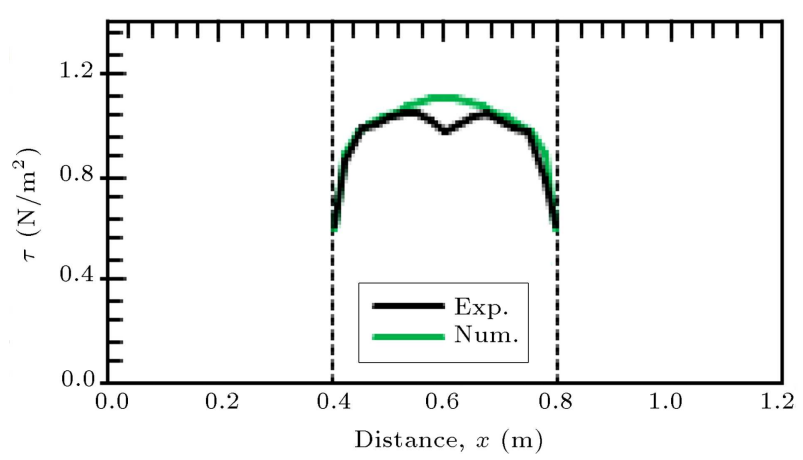

(c)

Figure 12. Boundary shear stress modelled using $k-\varepsilon$ turbulence model along convergence portion for an experimental series of NPC2-0.3: (a) $z=12 \mathrm{~m}$, (b) $z=13$ $\mathrm{m}$, and (c) $z=14 \mathrm{~m}$.

The average errors between experimental and numerical data of boundary shear stress for convergence angles of $3.81^{\circ}$ and $11.38^{\circ}$ are $13.53 \%$ and $13.18 \%$, respectively.

At the end of the narrowing reach, similar to the depth-averaged velocity distributions, the $k-\varepsilon$ turbulence model shows two local peaks near the main channel walls. Those local peaks verify the presence of two strong secondary circulations in the main channel.

\subsection{Secondary flow}

The secondary flow patterns for compound channels with narrowing floodplains, convergence angles of $11.31^{\circ}$, and relative depth of $D_{r}=0.5$ (NPC6-0.5) in three sections are modelled using the $k-\varepsilon$ turbulence model (see Figure 15).

The figures clearly show that by changing floodplain geometry along the converging part of the flume,

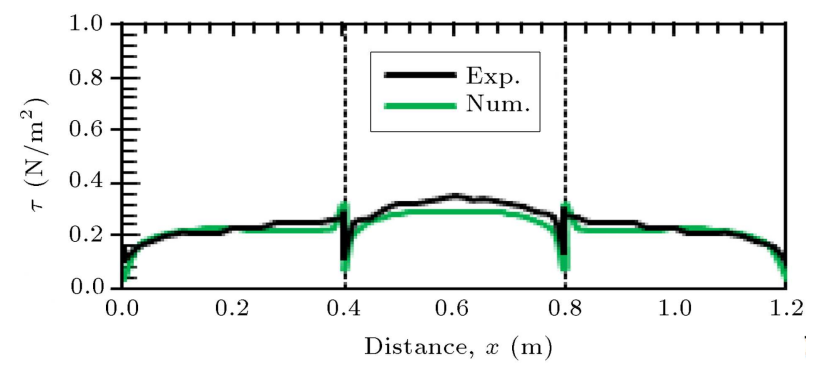

(a)

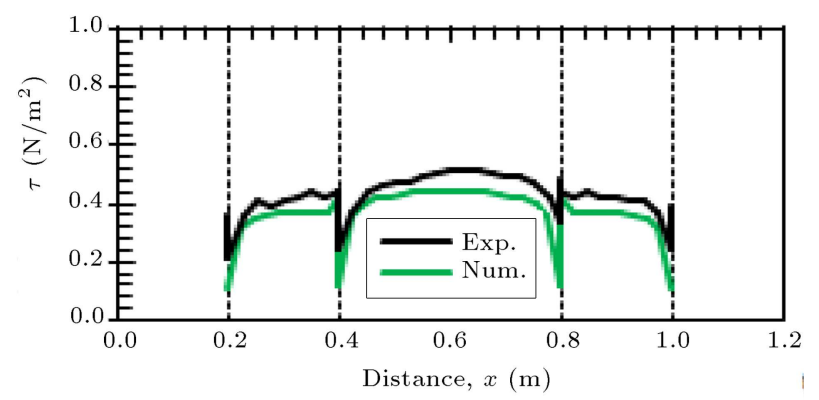

(b)

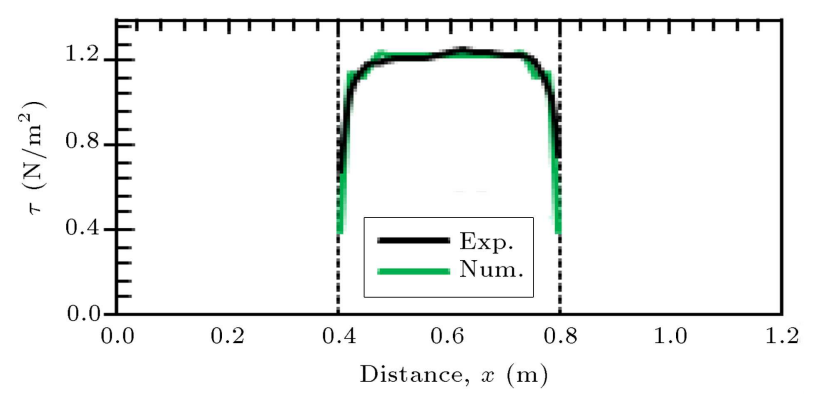

(c)

Figure 13. Boundary shear stress modeled using $k-\varepsilon$ turbulence model along convergence portion for an experimental series of NPC6-0.5: (a) $z=8 \mathrm{~m}$, (b) $z=11$ $\mathrm{m}$, and (c) $z=14 \mathrm{~m}$.

flow leaves the floodplain and crosses over flow in the main channel. In the second half part of the convergence reach, interaction between flows in the main channel and lateral flows through floodplains creates a strong secondary flow circulation near the main channel wall (see Figure 15(b) and (c)). It should be noted that Rezaei and Knight [7] did not study the secondary flow cell; however, the flow circulations simulated by the $k-\varepsilon$ turbulence model are in agreement with Bousmar [3] (see Figure 1). It is emphasized herein that the secondary flow cells interacting near the interface are responsible for a local increase of shear stress near the main channel walls.

\subsection{Water surface profile}

Predicting a water surface profile is a very important factor in the flood-risk management studies. It is also crucial to assess ecological effects of bridge construction or change the cross-section geometry of channels. The water depth is investigated numerically in a non- 


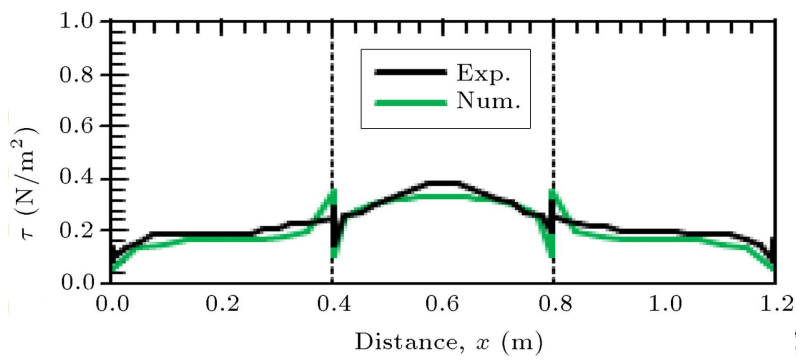

(a)

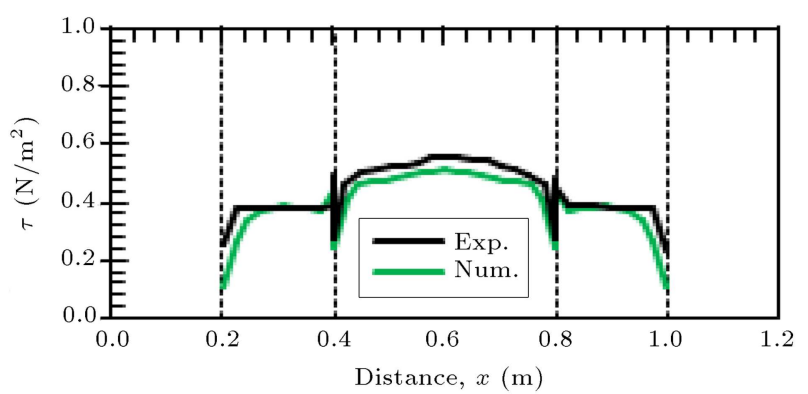

(b)

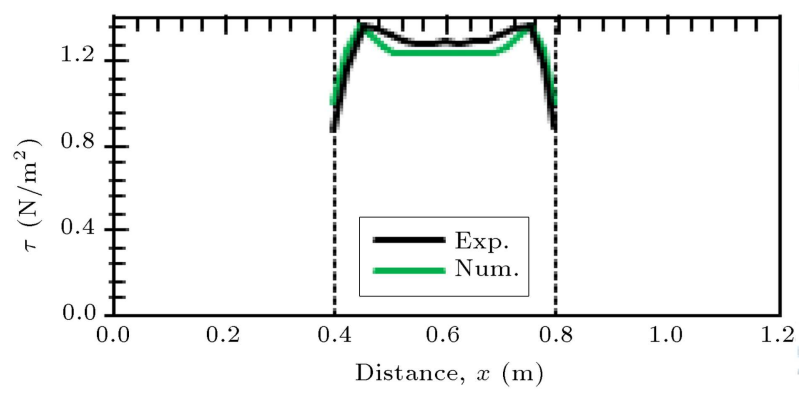

(c)

Figure 14. Boundary shear stress modeled using $k-\varepsilon$ turbulence model along convergence portion for an experimental series of NPC2-0.5: (a) $z=12 \mathrm{~m}$, (b) $z=13$ $\mathrm{m}$, and (c) $z=14 \mathrm{~m}$.

prismatic compound channel with two convergence angles of $3.81^{\circ}$ and $11.31^{\circ}$; besides, the results of modelling were then compared to the experimental data (see Figure 16).

Figure 16 shows that, in an upstream prismatic part of flume, there is good agreement between the measured water surface profiles and those calculated by the numerical modelling, especially for relative depth of 0.5. For both experimental tests, there are discrepancies between calculated and measured water surface profiles in the second half of the convergence reach.

As seen in Figure 16, the water surface profile can be divided into three following parts of the flume. Firstly, in the prismatic part of the flume, the presence of M1 water surface profile is apparent. Secondly, in the converging part of the flume, due to the flow acceleration, the water surface profile declines. Thirdly, in the downstream prismatic part of the flume, there is an almost uniform flow.

The fluctuations in the experimental water sur-

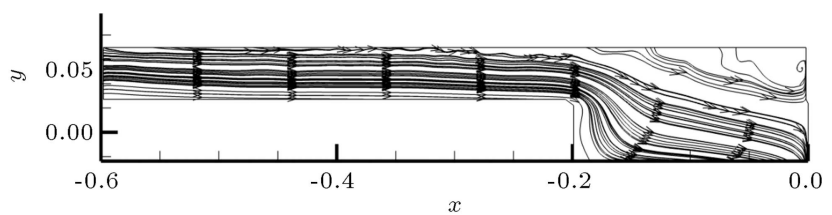

(a)

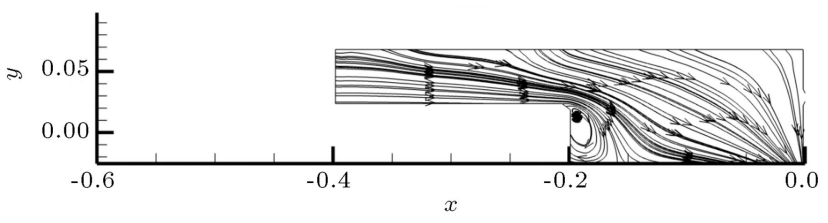

(b)

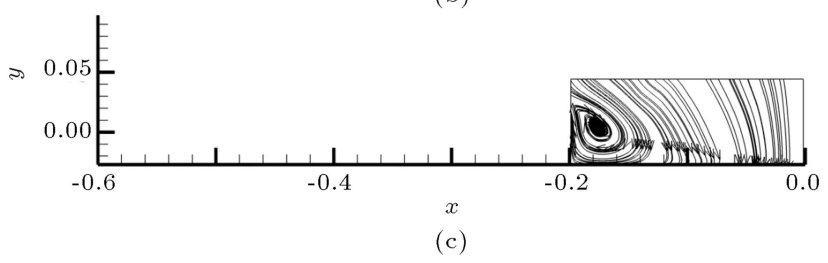

Figure 15. Secondary current circulations predicted using $k-\varepsilon$ turbulence mode along the convergence reach for an experimental series of NPC2-0.5: (a) $z=12 \mathrm{~m},(\mathrm{~b})$ $z=13 \mathrm{~m}$, and (c) $z=14 \mathrm{~m}$

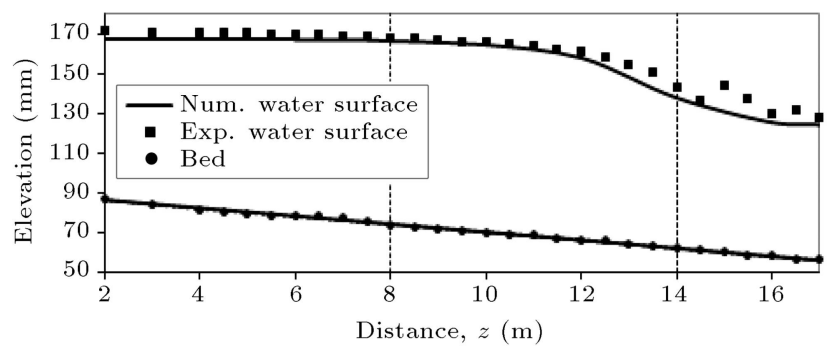

(a)

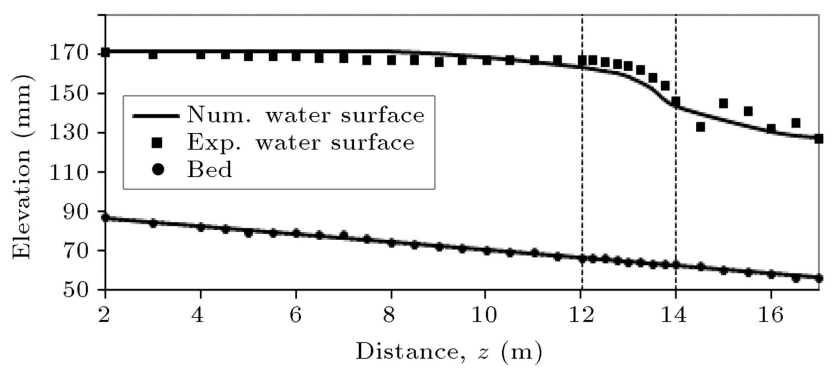

(b)

Figure 16. Comparison of water surface profiles calculated using $k-\varepsilon$ turbulence model and measured along the flume for two experimental series of (a) NPC6-0.5 and (b) NPC2-0.5.

face profile are due to cross-waves generated by the angle between the converging and prismatic parts of the flume [1].

\section{Conclusion}

The flow field in the compound channel with nonprismatic floodplains converging from $0.4 \mathrm{~m}$ to $0 \mathrm{~m}$ 
along $6 \mathrm{~m}$ and $2 \mathrm{~m}$ (convergence angles of $3.81^{\circ}$ and $\left.11.31^{\circ}\right)$ was numerically modelled using the $k-\varepsilon$ turbulence model. The results of modelling were then compared to the experimental data. The main findings of the research are listed below:

1. The $k-\varepsilon$ turbulence model is able to model velocity and boundary shear stress distributions along the converging part of the flume fairly well, especially for convergence angle of $3.81^{\circ}$;

2. By raising the convergence angle from $3.81^{\circ}$ to $11.31^{\circ}$, disagreement between numerical and experimental results of boundary shear stress and velocity distribution increases; however, as relative depth rises from 0.3 to 0.5 , the results of modelling improve significantly;

3. The $k-\varepsilon$ turbulence model cannot model the secondary flow created by anisotropy of turbulence structure; however, in case of compound channels with narrowing floodplains, the $k-\varepsilon$ model clearly shows the presence of strong secondary flow circulations in the second half of the convergence reach;

4. Water surface profile has been modelled using the $k-\varepsilon$ turbulence model and shown promising results, especially for relative depth of 0.5 .

\section{References}

1. Rezaei, B. "Overbank flow in compound channels with prismatic and non-prismatic floodplains", PhD Thesis, Birmingham University, UK (2006).

2. Tominaga, A. and Nezu, I. "Turbulent structure in compound open-channel flows", Journal of Hydraulic Engineering, 117(1), pp. 21-41 (1991).

3. Bousmar, D. "Flow modeling in compound channels -Momentum transfer between main channel and prismatic or non-prismatic floodplains", $\mathrm{PhD}$ Thesis, Universite Catholique de Louvain, Belgium (2002).

4. Bousmar, D. and Zech, Y. "Momentum transfer for practical flow computation in compound channel", Journal of Hydraulic Engineering, 125(7), pp. 696-706 (1999).

5. Bousmar, D., Wilkin, N., Jacquemart, J.H., and Zech, Y. "Overbank flow in symmetrically narrowing floodplains", Journal of Hydraulic Engineering, 130(4), pp. 305-312 (2004).

6. Proust, S., Rivière, N., Bousmar, D., Paquier, A., Zech, Y., and Morel, R. "Flow in compound channel with abrupt floodplain contraction", Journal of Hydraulic Engineering, 132(9), pp. 958-970 (2006).

7. Rezaei, B. and Knight, D.W. "Overbank flow in compound channels with non-prismatic floodplains", Journal of Hydraulic Engineering, 137(8), pp. 815-824 (2011).

8. Bousmar, D. and Zech, Y. "Discussion of twodimensional solution for straight and meandering over- bank flows", D.A. Ervine, K. Babaeyan-Koopaei, and Robert H.J. Sellin, Journal of Hydraulic Engineering, 126(9), pp. 653-669 (2000); Journal of Hydraulic Engineering, 128(5), pp. 550-551 (2002).

9. Pezzinga, G. "Velocity distribution in compound channel flows by numerical modeling", Journal of Hydraulic Engineering, 120(10), pp. 1176-1197 (1994).

10. Kang, H. and Choi, S.U. "Turbulence modeling of compound open-channel flows with and without vegetation on the floodplain using the Reynolds stress model", Advances in Water Resources, 29, pp. 16501664 (2006).

11. Cokljat, D. "Turbulence models for non-circular ducts and channels", PhD Thesis, City University London, UK (1993).

12. Wright, N.G., Crosseley, A.J., Morvan, H.P., and Stoesser, T. "Detailed validation of CFD for flows in straight channels", River Flow, Naples, Italy (2004).

13. Beaman, F. "Large eddy simulation of open channel flows for conveyance estimation", PhD Thesis, Nottingham University, UK (2010).

14. Bombardelli, F.A., Meireles, I., and Matos, J. "Laboratory measurements and multi-block numerical simulations of the mean flow and turbulence in the nonaerated skimming flow region of steep stepped spillways", Environmental Fluid Mechanics, 11(3), pp. 263-288 (2011).

15. Bayon, A., Valero, D., Bartula, R.G., Moran, F.J.V., and Jimenez, P.A.L. "Performance assessment of OpenFOAM and FLOW-3D in the numerical modeling of a low Reynolds number hydraulic jump", Environmental modelling \& Software, 80, pp. 322-335 (2016).

16. Gholami, A., Akhtari, A.A., Minatour, Y., Bonakdary, H., and Javadi, A.A. "Experimental and numerical study on velocity field and water surface profile in a strongly-curved $90^{\circ}$ open channel bend", Journal of Engineering Applications of Computation fluid $\mathrm{Me}$ chanics, 8(3), pp. 447-461 (2014).

17. Patel, V.C. "Calibration of the Preston tube and limitations on its use in pressure gradients", Journal of Fluid Mechanics, 23, pp. 85-208 (1965).

18. Davidson, P.A., Turbulence - An Introduction for Scientists and Engineers, Oxford University Press, UK (2004)

19. Launder, B.E. and Spalding, D.B. "The numerical computation of turbulent flows", Computer Method and Application and Engineering, 3(2), pp. 269-289 (1974).

20. Versteeg, H.K. and Malalasekera, W. "An introduction to computational fluid dynamics", The Finite Volume Method, 2nd Edn., Pearson Education Limited, Essex, England (2007).

21. Bonakdari, H., Baghalian, S., Nazari, F., and Fazli, M. "Numerical analysis and prediction of the velocity field in curved channel using artificial neural network and genetic algorithm", Journal of Engineering Applications of Computation fluid Mechanics, 5(3), pp. 384-396 (2011). 
22. Morvan, N., Pender, G., Wright, N.G., and Ervine, D.A. "Three-Dimensional hydrodynamics of meandering compound channels", Journal of Hydraulic Engineering, 128(7), pp. 674-682 (2002).

23. Hirt, C.W. and Nichols, B.D. "Volume of fluid (VOF) method for the dynamics of free boundaries", Journal of Computational Physics, 39(1), pp. 201-225 (1981).

24. Celik, I.B., Ghia, U. and Roache, P.J. "Procedure for estimation and reporting of uncertainty due to discretization in CFD applications", ASME Journal of Fluids Engineering, 130(7), pp. 1-4 (2008).

\section{Biographies}

Bahram Rezaei is an Assistant Professor in Bu-Ali Sina University, Civil Engineering Department, where he has been a faculty member since 1994 . He received his BSc and MSc degrees from Tabriz University in 1990 and 1993, respectively, and, then, he obtained his PhD degree from Birmingham University, UK in 2006. He teaches fluid mechanics and hydraulics courses at undergraduate and hydrodynamics at postgraduate levels. The main areas of his research interests are in the analytical, experimental, and numerical studies of the flow field in compound channels with prismatic and non-prismatic floodplains.

Hamed Amiri is a graduate student in Water Engineering. He received his $\mathrm{MSc}$ degree from Bu-Ali Sina University in 2015. His research area is in velocity and boundary shear stress distributions in compound channels using numerical methods. 